\title{
Social and Economic Costs of Gambling Problems and Related Harm among UK
}

\section{Military Veterans}

Shaun Harris ${ }^{1}$, Rhys D. Pockett ${ }^{1}$, Glen Dighton ${ }^{2}$, Katie Wood $^{2}$, Cherie Armour ${ }^{3}$, Matt Fossey ${ }^{4}$, Lee Hogan ${ }^{5}$, Neil Kitchiner ${ }^{6,7}$, Justyn Larcombe ${ }^{8}$, Robert D. Rogers ${ }^{5}$, \& Simon Dymond ${ }^{2,9 *}$

${ }^{1}$ Swansea Centre for Health Economics, Swansea University, Singleton Campus, Swansea, SA2 8PP, United Kingdom.

${ }^{2}$ School of Psychology, Swansea University, Singleton Campus, Swansea, SA2 8PP, United Kingdom.

${ }^{3}$ Research Centre for Stress Trauma and Related Conditions (STARC), School of Psychology, Queen's University Belfast, David Keir Building, Belfast, BT9 5BN, United Kingdom.

${ }^{4}$ Veterans and Families Institute, Anglia Ruskin University, Chelmsford, CM1 1SQ, United Kingdom.

${ }^{5}$ School of Psychology, Bangor University, Bangor, LL57 2DG, United Kingdom.

${ }^{6}$ Veterans NHS Wales, Cardiff and Vale University Health Board, Cardiff, CF11 0SN, United Kingdom.

${ }^{7}$ Division of Psychological Medicine and Clinical Neurosciences, Cardiff University, Heath Park, Cardiff, CF14 4XN, United Kingdom.

${ }^{8}$ The Recovery Course, c/o Tonbridge Baptist Church, Derwent Road, Tonbridge, Kent, TN10 3HZ, United Kingdom.

${ }^{9}$ Department of Psychology, Reykjavík University, Menntavegur 1, Nauthólsvík, 101 Reykjavík, Iceland.

*Corresponding author: s.o.dymond@swansea.ac.uk; 01792295602 


\section{Contributorship}

SH, RDP, CA, MF, LH, NK, JL, RDR and SD designed the study. SH, RDP, GD, and KW collected the data and conducted the statistical analysis. SH, GD and SD completed the first draft of the manuscript and all authors contributed to and e approved the final manuscript.

\section{Funding}

This work was supported by a grant from Forces in Mind Trust (FiMT17/0510S).

\section{Competing Interests}

None.

\section{Acknowledgements}

We thank the UK Armed Forces charities and veterans' networks for their keen support of this research. 


\begin{abstract}
Introduction: Military veterans are at heightened risk of problem gambling. Little is known about the costs of problem gambling and related harm among UK Armed Forces (AF) veterans. We investigated the social and economic costs of gambling among a large sample of veterans through differences in healthcare and social service resource use compared with age- and gender-matched non-veterans from the UK AF Veterans' Health and Gambling Study.
\end{abstract}

Methods: An online survey measured sociodemographic characteristics, gambling experience and problem severity, mental health, and healthcare resource utilisation. Health care provider, personal social service, and societal costs were estimated as total adjusted mean costs and utility, with cost-consequence analysis of a single timepoint.

Results: Veterans in our sample had higher healthcare, social service, and societal costs, and lower utility. Veterans had greater contacts with the criminal justice system, received more social service benefits, had more lost work hours, and greater accrued debt. A cost difference of $£ 590$ (95\% CI: -£1,016, -£163) was evident between veterans with scores indicating problem gambling and those reporting no problems. Costs varied by problem gambling status.

Conclusions: Our sample of UK AF veterans have higher healthcare, social service, and societal costs than non-veterans. Veterans experiencing problem gambling are more costly but have no reduction in quality of life. 


\section{Key Messages}

- Gambling is a growing public health issue, with military veterans at heightened risk of harm.

- Little is known about the costs of problem gambling and related harm among UK military veterans.

- We investigated the social and economic costs of gambling among a large sample of UK veterans through differences in healthcare and social service resource use.

- Veterans had higher healthcare, social service, and societal costs, and lower utility.

- Veterans had greater contacts with criminal justice services, received more benefits, and had more lost work hours. Costs increased by gambling status.

- Overall, veterans experiencing problem gambling are more costly but experience no reduction in quality of life. 
Gambling is a growing public health concern with adverse impacts on the health and wellbeing of individuals, families, and society ${ }^{1}$. These adverse consequences include financial management problems and debt, loss of employment, relationship breakdown, poor health, contact with the criminal justice system, disrupted educational attainment, and reduced social opportunities.

The social and economic costs of gambling harms are wide-ranging and difficult to estimate precisely ${ }^{2,3}$. To date, only one analysis has been conducted on the costs of gambling harms (specifically, on the costs of problem gambling) in the United Kingdom (UK). Thornley et al. ${ }^{4}$ estimated the excess fiscal costs of problem gambling in four domains: health services (primary care and associated services such as mental health) costs, welfare and employment costs, housing costs, and criminal justice costs. It was estimated that problem gambling costs the UK between $£ 260$ million and $£ 1.6$ billion. This is, however, likely to be a conservative estimate; in Australia, for instance, where a broader public health approach has long been adopted to calculating costs, the cost of gambling harms is estimated at AUSD\$4.7 billion a year ${ }^{5}$.

Gambling harms and associated social-economic costs disproportionately impact vulnerable populations. Military veterans are at heightened risk of problematic gambling, with rates of lifetime problem gambling considerably higher than the general population ${ }^{6}$. Indeed, the military population is over-represented by groups with typically lower rates of treatment seeking including younger men and those from lower socio-demographic groups ${ }^{7}$. Gambling problems among the general population also tend to co-occur with mental health conditions such as anxiety and depression and are associated with prior traumatic experience which can lead to posttraumatic stress disorder $(\mathrm{PTSD})^{8}$. Veterans are at greater risk of being exposed to traumatic events compared to the general population ${ }^{9}$, with exposure known to increase vulnerability to problem gambling ${ }^{10}$, which may require health and social care 
support long after discharge from the armed forces (AF). Veterans are also less likely to be employed, and more likely to be unemployed than the general population, with $10 \%$ of UK veterans experiencing financial difficulties including household arrears and debt after leaving the forces ${ }^{11}$.

Taken together, these risk factors and comorbid mental health difficulties may contribute to the social and economic burden of gambling-related harm among veterans. The costs of post-deployment screening for mental illness in UK veterans are considerably higher for those reporting psychiatric comorbidity ${ }^{12}$. However, mental health assessments do not currently include gambling. As a result, little is known about the costs of gambling-related harm in veterans.

The present study sought to assess, for the first time, the social and economic costs of problem gambling among veterans through differences in healthcare usage and social service provision between a sample of UK AF veterans and age- and gender-matched non-veterans. Using survey data collected as part of the UK AF Veterans' Health and Gambling Study ${ }^{13}$, we first measured resource use using groups of social costs before conducting costconsequence analysis of problem gambling-related harm.

\section{Methods}

\section{Study Design and Participants}

The UK AF Veterans' Health and Gambling Study is an age- and gender-matched cross-sectional online survey of UK citizens no longer serving (veterans) or those who have never served in the military (non-veterans). Participants were recruited primarily online through social media (e.g., targeted adverts on Facebook), via recruitment calls circulated by NHS veterans' services, charities, and Prolific (an online research participation platform). Veterans and non-veterans were a minimum of 18 years old and not currently serving in the 
UK AF. Non-veterans were domiciled within the UK, while veterans with a valid service number but had emigrated since leaving the AF were included. Primary outcome measures of relevance to the present study included gambling severity, mental health (e.g., anxiety, depression, PTSD), and healthcare utilisation. A total of 5,147 responses were received (2,535 veterans and 2,612 non-veterans); after quality control measures were applied, a final sample of 2,185 resulted ( $n=1,037$ veterans and $n=1,148$ non-veterans, respectively). Participants provided prior informed consent and the study was approved by Wales NHS Research Ethics Committee 6 (REC reference 19/WA/0134).

\section{Outcome Measures}

Sociodemographic characteristics. Respondents were asked their gender, age, ethnicity, marital status, highest qualification, accommodation type, and who they lived with. Veterans provided further details about their military service including length of service in years and branch.

Gambling participation and severity. Respondents were asked whether they had participated in one or more of 19 gambling activities within the past year (Supplementary Table 1). If participants had gambled, they completed the Problem Gambling Severity Index (PGSI) $^{14}$. The PGSI comprises nine items measuring potentially problematic gambling. Respondents rated how often in the past year they had experienced a particular behaviour (e.g., 'Have you bet more than you could really afford to lose?'), ranging from 'Never' (0) to 'Almost Always' (3). PGSI scores are summed, with 0 indicative of non-problem gambling, scores of 1-2 are classified as low-risk gambling, scores of 3-7 indicate moderate-risk gambling, and scores of 8 or above indicate problem gambling.

Mental health. For the present study, only three of the relevant mental health variables are described. First, the Patient Health Questionnaire (PHQ-9) ${ }^{15}$ was used to screen for depression. Second, the Generalised Anxiety Disorder assessment (GAD-7) ${ }^{16}$ screened for 
generalised anxiety disorder. Finally, the International Trauma Questionnaire (ITQ) ${ }^{17}$, which assessed post-traumatic stress disorder (PTSD) and complex PTSD, was also administered. Scores on these three questionnaires were included as co-variates in the economic analysis (see below).

\section{Healthcare Utilisation and Costs Analysis}

Health and social care utilisation. A version of the Client Service Receipt Inventory $(\mathrm{CSRI})^{18}$ measured NHS and social service utilisation (e.g., whether the participant has accessed their GP in the last 3 months). Dichotomous yes/no response options were given, along with the number of contacts, and free-text boxes for further clarifying information.

Employment, benefits, and debt. Primary components of the CSRI were used to assess employment status, hours worked, length of time in current job, days off sick in the past twelve months, monthly net income, any state benefits (and, if so, the type of benefits), and the number, type, and amount of priority and non-priority debts, if any.

Criminal justice contact. Respondents were asked if they had contact with the criminal justice system (e.g., with the police) in the past 3 months and whether they had ever been convicted of a criminal offence and, if so, the nature of the offence.

Health-related quality of life. The European Quality of Life in 5 Dimensions, 5 Level (EQ-5D-5L) ${ }^{19}$ scale assessed perceived quality of life across 5 domains: mobility, selfcare, activities of daily living, pain/discomfort, and anxiety/depression. Respondents selected whether they had 'no problems', 'slight problems', 'moderate problems', 'severe problems', were unable to walk/wash or dress oneself/perform usual activities, or experienced extreme pain/discomfort or were extremely anxious or depressed. Utility values were generated from the EQ-5D-5L, using the validated mapping function ${ }^{20}$ to existing EQ-5D-3L UK tariffs.

Respondents also indicated their perceived current health on a visual analogue scale ranging from 0 (the worst health you can imagine) to 100 (the best health you can imagine). 


\section{Economic Analysis}

The analysis compared costs and outcomes for veterans by gambling status (PGSI score). Resource use for the 3-month horizon was grouped by service type and group with mean number of contacts alongside $95 \%$ confidence intervals. Unit costs were obtained from published sources (Supplementary Table 2) ${ }^{21-28}$. For each item, the total cost was calculated by multiplying resource use by the unit costs and summed for each participant. Total costs were calculated from two perspectives: health care provider (HCP) and personal social service (PSS) and societal. Total adjusted mean costs and utility, and differences between groups of veterans differing by gambling status, were estimated using seemingly unrelated regressions accounting for the correlation between costs and outcomes. Costs and utilities were adjusted for age group, ethnicity, country of residence, qualifications, relationship status, and PHQ-9 and GAD-7 total scores as covariates. Analyses were verified by an independent statistician and conducted using Stata 16.

As the study considered a single timepoint, a cost-consequence analysis (CCA) was conducted which presents costs alongside a range of outcomes allowing decision makers to form their own opinion on their comparative relevance and importance ${ }^{29}$. Cost-consequence analyses are recommended where an intervention has a range of health and non-health benefits which may be difficult to measure or quantify ${ }^{30,31}$. Although mean EQ-5D-5L utility values were calculated for each arm, data was only available for a single timepoint, therefore it was not possible to calculate quality adjusted life years (QALYs).

\section{Results}

\section{Sociodemographic characteristics}

Table 1 shows the sociodemographic profile for the veterans $(n=1,037)$ and nonveterans $(n=1,148)$ from the UK AF Veterans' Health and Gambling Study. Most veterans in the sample were male (93.5\%), aged 30-29 (33.4\%), from England (77.6\%), married (49.2\%), 
in paid employment (67.9\%) and had achieved at least GCSEs A*-C qualification (30.0\%). Most non-veterans were male (91.8\%), aged 30-39 (33.4\%), from England (84.1\%), married (38.3\%), in paid employment (70.6\%), and had a Bachelor's degree as their highest earned qualification $(30.9 \%)$.

\section{**TABLE 1 HERE**}

\section{Gambling}

Table 2 describes the gambling status of the veterans and non-veterans' samples. Most veterans experienced problem gambling (43.1\%), whereas most non-veterans had experienced non-problem gambling (67.0\%). Veterans were 10.88 times more likely to experience problem gambling than non-veterans $(6.5 \%)$.

**TABLE 2 HERE**

\section{Healthcare resource utilisation}

For the primary analysis, complete societal data was available for $n=1,686(77.2 \%)$ participants. Imputation of missing data was not conducted. Resources used over the three months varied between veterans and non-veterans, with veterans generally reporting higher levels of healthcare resource use (Tables 3 and 4). Veterans had a higher number of inpatient admissions ( 0.08 versus 0.02$)$, outpatient visits ( 0.59 versus 0.29$)$, and emergency department attendances $(0.06$ versus 0.03$)$ compared to non-veterans. There was also a greater number of General Practice (GP) visits (0.46 versus 0.16$)$ and other primary care contacts among veterans, along with more contacts with physiotherapists $(0.24$ versus 0.08$)$, psychologists (0.29 versus 0.04$)$, and counsellors $(0.23$ versus 0.17$)$. Non-veterans had a higher number of prescribed medications ( 0.97 versus 0.90$)$. Notably, veterans had more contacts with gambling support ( 0.09 versus 0.01$)$, substance misuse ( 0.10 versus 0.01$)$, and alcohol misuse services $(0.17$ versus 0.01$)$. Contacts with criminal justice services were also higher for veterans $(0.12$ versus 0.03$)$. Veterans lost a greater number of hours from work (32.7 versus 
18.3), received a greater number of benefits (1.08 versus 0.48$)$, and had a higher amount of debt owed ( $£ 1,375$ versus $£ 806)$.

\section{**TABLES 3 AND 4 HERE**}

\section{Cost-consequence analysis}

Considering veterans' gambling status (PGSI score), adjusted mean costs were lower for veterans with scores indicating problem gambling (PGSI $\geq 8$ ) compared to no problem gambling or low-moderate risk of problem gambling (Table 5). A cost difference of $£ 590$ (95\% CI: -£1016, -£163) was observed between veterans with scores indicating problem gambling and those with no problems ( $£ 287$ versus £877). Conversely, from a societal perspective, veterans with higher PGSI scores had higher costs; however, differences between veterans without gambling problems and the remaining gambling status groups were not statistically significant. A cost difference of $£ 137$ (95\% CI: -£659, £933) was observed between those veterans with scores indicating problem gambling and those with no problems (£2336 versus £2199). Veterans with higher PGSI scores had greater costs associated with benefits received and lost work costs. Utility was higher for veterans with problem gambling behaviours compared to those with no problems ( 0.84 versus 0.72$)$, with similar differences observed for perceived current health (82.4 versus 72.2$)$ and with an approximate linear relationship by gambling status (Table 5).

**TABLE 5 HERE**

\section{Discussion}

The present study reports the first investigation of the social and economic costs of gambling-related harm and the costs-consequences of problem gambling among UK AF veterans. We measured healthcare resource utilisation, criminal justice contact, and the social costs incurred by veterans and conducted cost-consequence analysis of the costs of these 
harms in veterans differing by gambling status. Generally, veterans had higher utilisation of healthcare services such as inpatient stays, visits to GPs, and contact with social workers than non-veterans. Veterans also had greater contact with the police, lost more work hours, were in receipt of more benefits and had amassed larger debts than non-veterans. The costconsequence analysis revealed that veterans incurred substantially higher HCP/PSS and societal costs than non-veterans, while their adjusted mean costs decreased by gambling status and their utility scores rose as problem gambling severity scores increased.

Veterans are assumed to be reluctant to seek health and social care support ${ }^{7}$, yet these findings suggest our veteran sample was largely treatment-seeking ${ }^{32}$. The differences we found in healthcare resource utilisation and costs between veterans and non-veterans are likely to indicate an imbalance mediated by the impact of military service which is known to be associated with greater physical and mental needs, and for which veterans are already likely to be in receipt of support. It is important therefore to better understand the needs of treatment-seeking UK veterans and our findings suggest that gambling and related healthharming behaviour warrant further investigation.

The present analysis has several strengths. First, it extends existing health-economic analysis to dimensional categories of gambling status (PGSI score) over just problem gambling with veterans known to be at heightened risk of gambling harm. By so doing, it provides a fuller picture of the range of health-harming behaviours caused by gambling in veterans and the costs incurred. Second, our analysis was drawn from a large online sample of possibly self-selected, and help-seeking, veterans and a comparison group of age- and gender-matched non-veterans from across the UK. As such, the results may be considered at least partially representative of the national veteran community and is consistent with international evidence from similar treatment-seeking samples in the USA, Canada, and Australia. Further replication and extension with other samples is however needed. Third, the 
analysis provides a detailed demographic breakdown of this sample drawn from the UK AF veterans population. Finally, while noteworthy, the cost estimates are likely to be conservative as data were partially collected during the COVID-19 pandemic and could be higher as restrictions are eased and the demands for healthcare support increase $\mathrm{e}^{33}$.

Our findings support an economic case for screening for gambling-related harm among UK AF veterans. The costs of routine post-deployment and end of service screening are relatively low ${ }^{12}$. However, while costs may increase for those identified with mental health conditions, there is an obvious trade-off in the costs saved from future healthcare resource use, as well as criminal justice contact and accrued debt. Notwithstanding the absence of standardised screening tools for problem gambling risk, our findings indicate that engaging all healthcare professionals working with veterans as part of support for other, comorbid difficulties such as mental health problems and alcohol and substance use is needed to better understand the trajectory of gambling-related harms ${ }^{6,34}$.

The economic analysis is subject to limitations. First, data were collected at a single timepoint making it impossible to calculate QALYs. Second, the analysis is predominantly descriptive due to limitations on the available data. An incremental cost-utility analysis would provide further insight regarding the benefit of interventions targeted at veterans. Third, greater healthcare costs for veterans are likely to indicate exposure to greater physical and mental problems for this group. Future economic studies within these populations (e.g., in non-help-seeking veterans) should seek to collect baseline costs to control for these differences. Fourth, further research should seek to incorporate standardised health and wellbeing measures such as the Short-Form Health Survey ${ }^{35}$ in addition to gambling-specific outcomes and social costing. Finally, our findings cannot infer causality (i.e., whether the outcomes measured were the result of gambling or the other way around) and, to that extent, are merely statements of association or predictability. 
In conclusion, cost-consequences analysis showed that UK AF veterans have higher healthcare, social service, and societal costs, and have lower utility. Veterans have greater contacts with criminal justice services, receive more social service benefits, and have more lost work hours. From a societal perspective, veterans with problems gambling are more costly but experience no reduction in quality of life. 


\section{References}

1. Wardle H, Reith G, Langham E, et al. Gambling and public health: We need policy action to prevent harm. BMJ 2019; 365:11807. doi: 10.1136/bmj.11807

2. Patel A, McDaid D. Methods for assessing costs of gambling related harms and costeffectiveness of interventions. Care Policy and Evaluation Centre, UK; 2019.

3. Winkler P, Bejdova M, Csemy L, et al. Social costs of gambling in the Czech Republic 2012. J Gambling Studies. 2017; 33:1293-310.

4. Thorley C, Stirling A, Huynh, E. Cards on the table: The cost to government associated with people who are problem gamblers in Britain. Institute for Public Policy Research, UK; 2016.

5. Browne M, Greer N, Armstrong T, et al. The social cost of gambling to Victoria. Victorian Responsible Gambling Foundation, Melbourne; 2017.

6. Etuk R, Shirk SD, Grubbs J, et al. Gambling problems in US military veterans. Curr Addict Rep. 2020; 7:210-28.

7. Iversen AC, van Staden L, Hughes JH, et al. The stigma of mental health problems and other barriers to care in the UK Armed Forces. BMC Health Serv Res 2011; 11:31.

8. Rodriguez-Monguio R, Brand E, Volberg R. The economic burden of pathological gambling and co-occurring mental health and substance use disorders. J Addict Med 2018; $12: 53-60$

9. Palmer L, Thandi G, Norton S, et al. Fourteen-year trajectories of posttraumatic stress disorder (PTSD) symptoms in UK military personnel, and associated risk factors. $J$ Psychiatr Res. 2019; 109:156-63.

10. Dighton G, Roberts E, Hoon AE, et al. Gambling problems and the impact of family in UK Armed Forces veterans. J Behav Addict 2018; 7:355-65.

11. The Royal British Legion. A UK household survey of the ex-service community. London, $\mathrm{UK} ; 2014$.

12. Osumili B, McCrone P, Burdett H, et al. Cost of post-deployment screening for mental illness in the UK military: Findings from a cluster randomised controlled trial. J Ment Health 2019; doi:10.1080/09638237.2019.1581332

13. Dighton G, Wood K, Armour C, et al. Gambling problems among United Kingdom armed forces veterans: Associations with military service, mental health, gambling motivation, and posttraumatic stress disorder. Manuscript submitted for publication. 
14. Ferris JA, Wynne HJ. The Canadian problem gambling index (1-59). Ottawa, ON: Canadian Centre on Substance Abuse; 2001.

15. Kroenke K, Spitzer RL, Williams JB. The PHQ-9: Validity of a brief depression severity measure. J Gen Intern Med. 2001; 16:606-13.

16. Spitzer RL, Kroenke K, Williams JB, Löwe B. A brief measure for assessing generalized anxiety disorder: The GAD-7. Arch Intern Med. 2006; 166:1092-97.

17. Cloitre M, Shevlin M, Brewin CR, et al. The International Trauma Questionnaire: Development of a self-report measure of ICD-11 PTSD and complex PTSD. Acta Psychiat Scand. 2018; 138:536-546.

18. Beecham J, Knapp M. Costing psychiatric interventions. In Thorncroft D, Measuring Mental Health Needs, pp. 200-24, London; 2001.

19. Herdman M, Gudex C, Lloyd A, et al. Development and preliminary testing of the new five-level version of EQ-5D (EQ-5D-5L). Qual Life Res 2011; 20:1727-36.

20. van Hout B, Janssen MF, Feng YS, et al. Interim scoring for the EQ-5D-5L: Mapping the EQ-5D-5L to EQ-5D-3L value sets. Value Health. 2012; 15:708-15.

21. British National Formulary. National Institute for Health and Care Excellence; 2021. https://bnf.nice.org.uk/

22. Curtis L, Burns A. Unit Costs of Health and Social Care 2013. Canterbury: Personal Social Services Research Unit, University of Kent; 2013.

23. Curtis L, Burns A. Unit Costs of Health and Social Care 2015. Canterbury: Personal Social Services Research Unit, University of Kent; 2015.

24. Curtis L, Burns A. Unit Costs of Health and Social Care 2019. Canterbury: Personal Social Services Research Unit, University of Kent; 2019

25. Curtis L, Burns A. Unit Costs of Health and Social Care 2020. Canterbury: Personal Social Services Research Unit, University of Kent; 2020.

26. Department of Health and Social Care. National Schedule of NHS Costs 2018 to 2019. 2019. https://www.england.nhs.uk/national-cost-collection/

27. UK Government. Benefit and pension rates 2021 to 2022. https://www.gov.uk/government/publications/benefit-and-pension-rates-2021-to2022/benefit-and-pension-rates-2021-to-2022

28. Office for National Statistics. Annual Survey of Hours and Earnings. https://www.ons.gov.uk/surveys/informationforbusinesses/businesssurveys/annualsurvey ofhoursandearningsashe 
29. Turner J, O'Cathain A, Knowles E, et al. Evaluation of NHS 111 Pilot Sites. Sheffield: University of Sheffield, Medical Care Research Unit; 2012.

30. Drummond MF, Sculpher MJ, Torrance GW, et al. Methods for the economic evaluation of health care programme. Third edition. Oxford: Oxford University Press, 2005.

31. National Institute for Health and Care Excellence (NICE). How NICE measures value for money in relation to public health interventions. Local Government Briefing, London, $\mathrm{UK} ; 2013$.

32. Murphy D, Busuttil W. Understanding the needs of veterans seeking support for mental health difficulties. BMJ Mil Health 2019; 166:211-3.

33. Zala D, Mosweu I, Critchlow S, et al. Costing the COVID-19 pandemic: An exploratory economic evaluation of hypothetical suppression policy in the United Kingdom. Value Health. 2020; 23:1432-7.

34. Garvey-Wilson AL, O’Gallagher KG, Liu X, et al. Demographic, behavioural, and proximal risk factors for gambling disorder in the US military. Am J Addict 2021; 1-9.

35. Ware J, Jr., Kosinski M, Keller SD. A 12-Item Short-Form Health Survey: construction of scales and preliminary tests of reliability and validity. Med Care. 1996; 34:220-33. 


\section{Tables}

Table 1. Sociodemographic characteristics of the veterans' and non-veterans' samples.

\begin{tabular}{|c|c|c|c|c|c|c|}
\hline \multirow[b]{3}{*}{ Gender } & \multicolumn{2}{|c|}{$\begin{array}{c}\text { Veterans } \\
(n=1,037)\end{array}$} & \multicolumn{2}{|c|}{$\begin{array}{c}\text { Non-veterans } \\
(n=1,148)\end{array}$} & \multirow{2}{*}{\multicolumn{2}{|c|}{$p$}} \\
\hline & \multirow[t]{2}{*}{$n$} & \multirow[t]{2}{*}{$\%$} & \multirow[t]{2}{*}{$n$} & \multirow[t]{2}{*}{$\%$} & & \\
\hline & & & & & & \multirow{4}{*}{.278} \\
\hline Male & 970 & 93.5 & 1054 & 91.8 & .123 & \\
\hline Female & 64 & 6.2 & 91 & 7.9 & .111 & \\
\hline Other & 3 & 0.3 & 3 & 0.3 & .901 & \\
\hline \multicolumn{7}{|l|}{ Age } \\
\hline $18-29$ & 63 & 6.1 & 73 & 6.4 & .788 & \multirow{7}{*}{1.00} \\
\hline $30-39$ & 346 & 33.4 & 383 & 33.4 & .986 & \\
\hline $40-49$ & 201 & 19.4 & 221 & 19.3 & .929 & \\
\hline $50-59$ & 222 & 21.4 & 246 & 21.4 & 1.00 & \\
\hline $60-69$ & 155 & 15.0 & 171 & 14.9 & .966 & \\
\hline $70-79$ & 40 & 3.9 & 45 & 3.9 & .943 & \\
\hline $80+$ & 9 & 0.9 & 9 & 0.8 & .827 & \\
\hline \multicolumn{7}{|l|}{ Country } \\
\hline England & 805 & 77.6 & 965 & 84.1 & $<.001^{*}$ & \multirow{5}{*}{$<.001^{\ddagger}$} \\
\hline Wales & 127 & 12.2 & 76 & 6.6 & $<.001^{*}$ & \\
\hline Scotland & 67 & 6.5 & 84 & 7.3 & .431 & \\
\hline Northern Ireland & 28 & 2.7 & 23 & 2.0 & .282 & \\
\hline Other & 10 & 1.0 & 0 & 0.0 & $.001^{*}$ & \\
\hline \multicolumn{7}{|l|}{ Ethnicity } \\
\hline White British & 960 & 92.6 & 1020 & 88.9 & \multirow{2}{*}{\multicolumn{2}{|c|}{$.003^{*}$}} \\
\hline Other & 77 & 7.4 & 128 & 11.1 & & \\
\hline \multicolumn{7}{|l|}{ Marital Status } \\
\hline Single & 103 & 9.9 & 243 & 21.2 & $<.001^{*}$ & \multirow{8}{*}{$<.001^{\ddagger}$} \\
\hline In a relationship & 95 & 9.2 & 160 & 13.9 & $.001^{*}$ & \\
\hline Co-habiting & 47 & 4.5 & 138 & 12.0 & $<.001^{*}$ & \\
\hline Married & 510 & 49.2 & 440 & 38.3 & $<.001^{*}$ & \\
\hline Married 2nd+ & 166 & 16.0 & 87 & 7.6 & $<.001^{*}$ & \\
\hline Separated & 25 & 2.4 & 22 & 1.9 & .426 & \\
\hline Divorced & 70 & 6.8 & 45 & 3.9 & $.003^{*}$ & \\
\hline Widowed & 21 & 2.0 & 13 & 1.1 & .092 & \\
\hline \multicolumn{7}{|l|}{ Highest Qualification a } \\
\hline No formal qualification & 63 & 6.1 & 24 & 2.1 & $<.001^{*}$ & \multirow{9}{*}{$<.001^{*}$} \\
\hline Entry certificate & 34 & 3.3 & 16 & 1.4 & $.003^{*}$ & \\
\hline GCSE D-G & 153 & 14.8 & 83 & 7.2 & $<.001^{*}$ & \\
\hline GCSE A*-C & 311 & 30.0 & 156 & 13.6 & $<.001^{*}$ & \\
\hline AS/A level & 153 & 14.8 & 199 & 17.3 & .101 & \\
\hline Certificate of HE & 125 & 12.1 & 87 & 7.6 & $<.001^{*}$ & \\
\hline Bachelor's degree & 116 & 11.2 & 355 & 30.9 & $<.001^{*}$ & \\
\hline Master's degree & 78 & 7.5 & 189 & 16.5 & $<.001^{*}$ & \\
\hline Doctorate & 4 & 0.4 & 39 & 3.4 & $<.001^{*}$ & \\
\hline
\end{tabular}

Notes: ${ }^{\text {a }}$ Qualification categories describe qualifications of equivalent level of attainment and may not be the qualification the respondent holds. $p=$ Significance of Pearson's $\chi^{2}$ test. ${ }^{\dagger}$ Indicates significance where $p<0.05 . \$$ Indicates significance where $p<0.01$ 
Table 2. Comparison of gambling severity between veterans and non-veterans.

\begin{tabular}{lcccccccc}
\hline & \multicolumn{3}{c}{ Veterans } & \multicolumn{3}{c}{ Non-veterans } & \multirow{2}{*}{$\boldsymbol{p}$} & \multirow{2}{*}{ OR (95\% CI) } \\
\cline { 2 - 6 } & $\mathbf{n}$ & $\mathbf{\%}$ & $\mathbf{n}$ & $\mathbf{\%}$ & & & \\
\hline Gambling Severity & 949 & & 815 & & & & \\
Non-problem gambling & 357 & 37.7 & 546 & 67.0 & $<.001^{\ddagger}$ & & $0.30(0.25-0.36)$ \\
Low-risk gambling & 80 & 8.4 & 125 & 15.3 & $<.001^{\ddagger}$ & $<.001 \ddagger$ & $0.51(0.38-0.69)$ \\
Moderate-risk gambling & 102 & 10.8 & 91 & 11.2 & .791 & $0.96(0.71-1.30)$ \\
Problem gambling & 408 & 43.1 & 53 & 6.5 & $<.001^{\ddagger}$ & $10.88(8.01-14.79)$ \\
\hline
\end{tabular}

Notes: Sample respondent totals reported for each measure. $p=$ Significance of Pearson's $\chi^{2}$ test. OR: unadjusted Odds Ratio. 95\% CI: Upper and lower bound 95\% confidence intervals. $\dagger$ Indicates significance where $\mathrm{p}<0.05$. Indicates significance where $\mathrm{p}<0.01$. 
Table 3: Total unadjusted mean resource use by veterans and non-veterans.

\begin{tabular}{|c|c|c|c|c|}
\hline $\begin{array}{l}\text { Resource Use Category } \\
\text { (unit of measurement) }\end{array}$ & $\mathbf{N}$ & $\begin{array}{l}\text { Veterans } \\
(95 \% \mathrm{CI})\end{array}$ & $\mathbf{N}$ & $\begin{array}{c}\text { Non-veterans } \\
(95 \% \mathrm{CI})\end{array}$ \\
\hline $\begin{array}{l}\text { A\&E attendances not resulting } \\
\text { in admission (number of } \\
\text { attendances) }\end{array}$ & 1037 & $\begin{array}{c}0.06 \\
(0.04,0.07)\end{array}$ & 1148 & $\begin{array}{c}0.03 \\
(0.02,0.04)\end{array}$ \\
\hline $\begin{array}{l}\text { A\&E attendances resulting in } \\
\text { admission } \\
\text { (number of attendances) }\end{array}$ & 1037 & $\begin{array}{c}0.05 \\
(0.04,0.07)\end{array}$ & 1148 & $\begin{array}{c}0.02 \\
(0.01,0.03)\end{array}$ \\
\hline $\begin{array}{l}\text { Inpatient stays } \\
\text { (number of stays) }\end{array}$ & 961 & $\begin{array}{c}0.08 \\
(0.07,0.10)\end{array}$ & 1136 & $\begin{array}{c}0.02 \\
(0.01,0.03)\end{array}$ \\
\hline $\begin{array}{l}\text { Outpatient appointments } \\
\text { (number of appointments) }\end{array}$ & 905 & $\begin{array}{c}0.59 \\
(0.54,0.64)\end{array}$ & 1080 & $\begin{array}{c}0.29 \\
(0.26,0.32)\end{array}$ \\
\hline $\begin{array}{l}\text { Day case attendance } \\
\text { (number of attendances) }\end{array}$ & 958 & $\begin{array}{c}0.16 \\
(0.14,0.19)\end{array}$ & 1135 & $\begin{array}{c}0.07 \\
(0.05,0.08)\end{array}$ \\
\hline $\begin{array}{l}\text { GP practice visits } \\
\text { (number of visits) }\end{array}$ & 919 & $\begin{array}{c}0.46 \\
(0.42,0.50)\end{array}$ & 1131 & $\begin{array}{c}0.16 \\
(0.14,0.19)\end{array}$ \\
\hline $\begin{array}{l}\text { GP phone calls } \\
\text { (number of phone calls) }\end{array}$ & 929 & $\begin{array}{c}0.57 \\
(0.53,0.63)\end{array}$ & 1129 & $\begin{array}{c}0.52 \\
(0.48,0.56)\end{array}$ \\
\hline $\begin{array}{l}\text { GP home visits } \\
\text { (number of visits) }\end{array}$ & 938 & $\begin{array}{c}0.05 \\
(0.04,0.07)\end{array}$ & 1131 & $\begin{array}{c}0.01 \\
(0.01,0.02)\end{array}$ \\
\hline $\begin{array}{l}\text { Nurse practice visits } \\
\text { (number of visits) }\end{array}$ & 931 & $\begin{array}{c}0.19 \\
(0.17,0.22)\end{array}$ & 1128 & $\begin{array}{c}0.22 \\
(0.20,0.25)\end{array}$ \\
\hline $\begin{array}{l}\text { GP provided clinics } \\
\text { (number of visits) }\end{array}$ & 929 & $\begin{array}{c}0.13 \\
(0.11,0.16)\end{array}$ & 1130 & $\begin{array}{c}0.05 \\
(0.04,0.06)\end{array}$ \\
\hline $\begin{array}{l}\text { GP out-of-hours service } \\
\text { (number of contacts) }\end{array}$ & 938 & $\begin{array}{c}0.04 \\
(0.02,0.05)\end{array}$ & 1132 & $\begin{array}{c}0.02 \\
(0.02,0.03)\end{array}$ \\
\hline $\begin{array}{l}\text { NHS Direct/111 phone service } \\
\text { (number of phone calls) }\end{array}$ & 936 & $\begin{array}{c}0.17 \\
(0.15,0.20)\end{array}$ & 1131 & $\begin{array}{c}0.10 \\
(0.08,0.12)\end{array}$ \\
\hline $\begin{array}{l}\text { Counsellor } \\
\text { (number of contacts) }\end{array}$ & 928 & $\begin{array}{c}0.23 \\
(0.20,0.26)\end{array}$ & 1132 & $\begin{array}{c}0.17 \\
(0.15,0.20)\end{array}$ \\
\hline $\begin{array}{l}\text { Physiotherapist } \\
\text { (number of contacts) }\end{array}$ & 933 & $\begin{array}{c}0.24 \\
(0.21,0.27)\end{array}$ & 1132 & $\begin{array}{c}0.08 \\
(0.06,0.10)\end{array}$ \\
\hline $\begin{array}{l}\text { Psychologist } \\
\text { (number of contacts) }\end{array}$ & 931 & $\begin{array}{c}0.29 \\
(0.26,0.33)\end{array}$ & 1133 & $\begin{array}{c}0.04 \\
(0.03,0.06)\end{array}$ \\
\hline $\begin{array}{l}\text { Charity support } \\
\text { (number of contacts) }\end{array}$ & 930 & $\begin{array}{c}0.26 \\
(0.23,0.30)\end{array}$ & 1133 & $\begin{array}{c}0.02 \\
(0.01,0.03)\end{array}$ \\
\hline $\begin{array}{l}\text { Home help/home care worker } \\
\text { (number of contacts) }\end{array}$ & 937 & $\begin{array}{c}0.34 \\
(0.31,0.38)\end{array}$ & 1133 & $\begin{array}{c}0.56 \\
(0.52,0.60)\end{array}$ \\
\hline $\begin{array}{l}\text { Social worker } \\
\text { (number of contacts) }\end{array}$ & 936 & $\begin{array}{c}0.17 \\
(0.14,0.20)\end{array}$ & 1132 & $\begin{array}{c}0.04 \\
(0.03,0.05)\end{array}$ \\
\hline $\begin{array}{l}\text { Mental health caseworker } \\
\text { (number of contacts) }\end{array}$ & 931 & $\begin{array}{c}0.34 \\
(0.31,0.38)\end{array}$ & 1133 & $\begin{array}{c}0.01 \\
(0.01,0.02)\end{array}$ \\
\hline
\end{tabular}


Self-help group

(number of contacts)

Community day care

(number of contacts)

Community mental health

centre

(number of contacts)

Other community care ${ }^{2}$

(number of contacts)

Gambling support

(number of contacts)

Alcohol misuse service

(number of contacts)

Substance misuse service

(number of contacts)

Prescribed medications

(number of medications) ${ }^{1}$

Total cost of medications ( $($ )

Total cost of medications

(>£1,000 medication costs) excluding high-cost patients

$\begin{array}{cccc}933 & 0.34 & 1131 & 0.16 \\ 936 & (0.30,0.38) & & (0.14,0.19) \\ & 0.02 & 1133 & 0.00 \\ 935 & (0.01,0.03) & & (0.00,0.01) \\ & 0.06 & 1133 & 0.02 \\ & (0.04,0.08) & & (0.02,0.04) \\ 913 & & & \\ & (1.72,1.89) & & 0.52 \\ 933 & 0.09 & 1133 & 0.01 \\ & (0.08,0.12) & & (0.01,0.02) \\ 937 & 0.17 & 1133 & 0.01 \\ & (0.15,0.20) & & (0.00,0.02) \\ 937 & 0.10 & 1133 & 0.01 \\ & (0.08,0.13) & & (0.00,0.01) \\ 943 & 0.90 & 1133 & 0.97 \\ & (0.84,0.96) & & (0.91,1.03) \\ 922 & 50.04 & 1128 & 53.78 \\ & (20.32,79.76) & & (20.32,79.76) \\ 914 & 17.14 & 1108 & 16.19 \\ & (13.50,20.79) & & (13.02,19.35)\end{array}$

${ }^{1}$ Details of over-the-counter medications were not collected. Any over-the-counter medications reported by participants were excluded from analysis.

${ }^{2}$ Other community care includes walk-in health service/minor injury unit visits, district nurse home visits, community nurse contacts, health visitor home visits, occupational therapist visits, speech therapist visits, other therapist visits, alternative medicine visits, and community support visits. 
Table 4: Criminal justice contacts and social costs (unadjusted mean resource use) for veterans and non-veterans.

\section{Resource Use Category (unit of measurement)}

\section{CRIMINAL JUSTICE}

\section{Any contact with police}

(number of contacts)

Overnight stays in police cell or prison (number of stays)

Psychiatric assessments in custody (number of assessments)

Criminal court appearances

(number of appearances)

Civil court appearances

(number of appearances)

Any probation service contacts

(number of contacts)

Community sentences served

(number of sentences served)

\section{SOCIAL COSTS}

Debt (amount owed (£))

Lost work hours

(number of hours)

Benefits received

(number of benefits)

Total cost of benefits received (£)
Veterans

$\mathbf{N}$

(95\% CI)

915

658

1010

1029

1029
$(0.09,0.14)$

$(0.01,0.04)$

$(0.01,0.03)$

$$
0.02
$$

$(0.01,0.03)$

$(0.04,0.07)$

$$
0.14
$$

$(0.11,0.16)$

$$
0.02
$$

$(0.01,0.04)$

$11,574.17$

$(10,400.48$,

$12,747.85)$

32.69

(26.42, 38.96)

1.08

$(0.97,1.19)$

1374.54

$(1,226.36,1,522.72)$
$\mathbf{N}$

1126

1126

1125

1126

1126

1126

1126

Non-veterans (95\% CI)

0.03

$(0.02,0.03)$

0

$(0.00,0.00)$

0

$(0.00,0.00)$

0.00

$(0.00,0.01)$

0.01

$(0.00,0.02)$

0.01

$(0.01,0.02)$

0.01

$(0.00,0.02)$

630

8907.10

$(7,415.82$,

10,398.38)

1120

18.34

$(14.82,21.87)$

$1153 \quad 0.48$

$(0.41,0.54)$

805.66

$(693.49,917.83)$ 
Table 5: Cost-consequences (costs, utility, and perceived current health) for veterans by gambling status $(95 \% \mathrm{CI})$.

\begin{tabular}{|c|c|c|c|c|c|c|c|}
\hline & $\mathbf{N}$ & Costs (£) & Utility & Health & 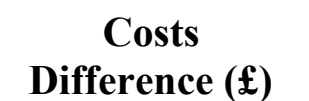 & $\begin{array}{c}\text { Utility } \\
\text { Difference }\end{array}$ & $\begin{array}{c}\text { Health } \\
\text { Difference }\end{array}$ \\
\hline \multicolumn{8}{|c|}{ Healthcare Provider/Personal Social Service Costs ${ }^{\mathrm{a}}$} \\
\hline $\begin{array}{l}\text { Non-problem gambling } \\
\text { (PGSI 0) }\end{array}$ & 215 & $\begin{array}{c}876.62 \\
(603.61,1,149.64)\end{array}$ & $\begin{array}{c}0.72 \\
(0.69,0.74)\end{array}$ & $\begin{array}{c}72.22 \\
(70.03,74.41)\end{array}$ & & & \\
\hline $\begin{array}{l}\text { Low-risk gambling } \\
\text { (PGSI 1-2) }\end{array}$ & 51 & $\begin{array}{c}601.07 \\
(100.72,1,101.42)\end{array}$ & $\begin{array}{c}0.75 \\
(0.70,0.79)\end{array}$ & $\begin{array}{c}76.60 \\
(72.59,80.61)\end{array}$ & $\begin{array}{c}-275.55 \\
(-829.51,278.42)\end{array}$ & $\begin{array}{c}0.03 \\
(-0.02,0.08)\end{array}$ & $\begin{array}{c}4.38 \\
(-0.07,8.82)\end{array}$ \\
\hline $\begin{array}{l}\text { Moderate-risk gambling } \\
\text { (PGSI 3-7) }\end{array}$ & 73 & $\begin{array}{c}457.44 \\
(40.80,874.07)\end{array}$ & $\begin{array}{c}0.80 \\
(0.76,0.84)\end{array}$ & $\begin{array}{c}73.22 \\
(69.88,76.56)\end{array}$ & $\begin{array}{c}-419.19 \\
(-916.94,78.57)\end{array}$ & $\begin{array}{c}0.08 \\
(0.03,0.12)\end{array}$ & $\begin{array}{c}1.00 \\
(-3.00,4.99)\end{array}$ \\
\hline Problem gambling (PGSI $\geq 8$ ) & 249 & $\begin{array}{c}286.79 \\
(26.85,546.74)\end{array}$ & $\begin{array}{c}0.84 \\
(0.82,0.87)\end{array}$ & $\begin{array}{c}82.39 \\
(80.30,84.47)\end{array}$ & $\begin{array}{c}-589.83 \\
(-1,016.31,-163.34)\end{array}$ & $\begin{array}{c}0.12 \\
(0.09,0.16)\end{array}$ & $\begin{array}{c}10.17 \\
(6.74,13.59)\end{array}$ \\
\hline $\begin{array}{l}\text { Societal Costs }^{\mathbf{a}} \\
\text { Non-problem gambling } \\
\text { (PGSI 0) }\end{array}$ & 213 & $\begin{array}{c}2,199.04 \\
(1,692.04,2,706.05)\end{array}$ & $\begin{array}{c}0.72 \\
(0.70,0.75)\end{array}$ & $\begin{array}{c}72.39 \\
(70.20,74.59)\end{array}$ & & & \\
\hline $\begin{array}{l}\text { Low-risk gambling (PGSI 1- } \\
\text { 2) }\end{array}$ & 48 & $\begin{array}{c}2,143.62 \\
(1,196.89,3,090.36)\end{array}$ & $\begin{array}{c}0.75 \\
(0.70,0.79)\end{array}$ & $\begin{array}{c}76.14 \\
(72.04,80.24)\end{array}$ & $\begin{array}{c}-55.42 \\
(-1,098.66,987.82)\end{array}$ & $\begin{array}{c}0.02 \\
(-0.03,0.08)\end{array}$ & $\begin{array}{c}3.74 \\
(-0.77,8.26)\end{array}$ \\
\hline $\begin{array}{l}\text { Moderate-risk gambling } \\
\text { (PGSI 3-7) }\end{array}$ & 71 & $\begin{array}{c}2,328.76 \\
(1,548.97,3,108.55)\end{array}$ & $\begin{array}{c}0.80 \\
(0.76,0.84)\end{array}$ & $\begin{array}{c}72.58 \\
(69.21,75.96)\end{array}$ & $\begin{array}{c}129.72 \\
(-800.04,1,059.48)\end{array}$ & $\begin{array}{c}0.08 \\
(0.03,0.13)\end{array}$ & $\begin{array}{c}0.19 \\
(-3.84,4.22)\end{array}$ \\
\hline Problem gambling (PGSI $\geq 8$ ) & 243 & $\begin{array}{c}2,335.72 \\
(1,849.15,2,822.29)\end{array}$ & $\begin{array}{c}0.85 \\
(0.82,0.87)\end{array}$ & $\begin{array}{c}82.91 \\
(80.80,85.02)\end{array}$ & $\begin{array}{c}136.68 \\
(-659.41,932.76)\end{array}$ & $\begin{array}{c}0.13 \\
(0.09,0.16)\end{array}$ & $\begin{array}{c}10.52 \\
(7.07,13.96)\end{array}$ \\
\hline
\end{tabular}

${ }^{a}$ Difference in adjusted means estimated using a seemingly unrelated regression model with age group, ethnicity, country of residence, qualifications, relationship status, PTSD status, armed forces branch, and PHQ9 and GAD7 total scores as covariates. 
GAMBLING RESEARCH, EDUCATION AND TREATMENT

$$
\begin{aligned}
& \text { Ymchwil lechyd } \\
& \text { a Gofal Cymru } \\
& \text { Health and Care } \\
& \text { Research Wales }
\end{aligned}
$$

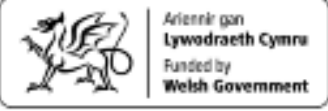

